\title{
CRP Levels in Viral Hepatitis: A Meta-Analysis Study
}

\author{
Sukhpal Singh ${ }^{1}$, Abhishek Bansal ${ }^{2,{ }^{*}}$ and Pardeep Kumar ${ }^{1}$ \\ ${ }^{1}$ Department of Biochemistry, M.M. Institute of Medical Sciences and Research, Maharishi Markandeshwar (Deemed to be University), Mullana Ambala, India \\ ${ }^{2}$ Department of Biochemistry, J.N. Medical College, KLE University, Belagavi, India \\ "Corresponding author: Department of Biochemistry, J.N. Medical College, KLE University, Belagavi, India. Email: bansalabhishek99@gmail.com
}

Received 2020 September 14; Revised 2020 October 16; Accepted 2020 October 19.

\begin{abstract}
Context: Viral hepatitis is a common infectious disorder with a high degree of mortality. The host immunological feedback to the hepatitis virus is dim and unable to down-regulate and clear infection. C-reactive protein (CRP), an acute phase reactant synthesized by hepatocytes in response to inflammatory reactions, facilitates apoptosis and phagocytosis. An effort has been made in the current meta-analysis study to elucidate the relationship between CRP and hepatitis B virus (HBV) and hepatitis C virus (HCV) infections. Methods: Eighteen published research articles on CRP levels of viral hepatitis patients were included in this study. A random-effects model was used to calculate the pooled mean level for CRP.

Results: The pooled mean level of CRP hepatitis B and hepatitis C was $6.93 \mathrm{mg} / \mathrm{L}$ (95\% CI:3.04 -10.81) and 2.31 mg/L(95\% CI:1.06 - 3.55), respectively. A high degree of variance was observed among the studies, with the $\mathrm{I}^{2}$ more than $90 \%$.

Conclusions: The pooled mean level of CRP was within the normal range in patients with hepatitis C; however, it was high in patients with hepatitis B. The pooled mean CRP level reported in this study can be useful to determine the level of liver damage in patients with viral hepatitis.
\end{abstract}

Keywords: C-Reactive Protein, Hepatitis B, Hepatitis C, Inflammation

\section{Context}

Viral hepatitis is a common bloodborne infection with a high rate of mortality, 1.4 million deaths globally every year. Five viruses, hepatitis A virus (HAV), hepatitis B virus (HBV), hepatitis C virus (HCV), hepatitis D virus (HDV), and hepatitis E virus (HEV) are responsible for this deadly disease. HBV and HCV account for $90 \%$ of the deaths, while the remaining are related to other viruses $(1,2)$. The routes of viral transmission are percutaneous or mucosal exposure to infected blood or body fluids, sexual intercourse, particularly in homosexual men, perinatal transmission, drug abuse in low endemic areas, and parenteral transmission (3).

Generally, the inflammatory response is useful for the host. Cellular inflammatory responses release cytokines to control cellular stress and minimize cellular damage in response to viral infection. The host immune responses to hepatitis viruses are weak and unable to down-regulate and clear the infection, which can activate the antigenspecific immune response in patients, leading to activation of lymphomononuclear cells in the liver resulting in fibrosis, cirrhosis, and/or hepatocellular carcinoma (HCC) (4).
C-reactive protein (CRP) $(0.1-5.0 \mathrm{mg} / \mathrm{L}$ of blood) is an acute phase reactant synthesized by hepatocytes in response to inflammatory reactions as a result of the innate immune response of the host that facilitates apoptosis and phagocytosis. In addition, CRP can also activate the classical complement pathway through binding to C1q protein. The production of CRP is regulated by proinflammatory cytokines, such as Interleukin 6 (IL-6), IL-1 $\beta$, tumor necrosis factor- $\alpha(5,6)$. Among these interleukins, IL- 6 is the most important inflammatory cytokine that regulates CRP gene expression. The CRP gene is located on chromosome 1. In hepatocytes, IL-6 induces CRP production at the transcription level, which is promoted by $\operatorname{IL}-1 \beta(5,7)$.

The results of in vitro experiments have indicated that HBV enhances the expression of the IL- 6 and IL-1- $\beta$ gene via transcriptional transactivation activity of hepatitis $B$ virus $\mathrm{X}$ protein (HBx) and CRP (7). However, it has also been reported that decreased production of CRP in patients chronically infected with HCV decreased the level of CRP gene expression (8). Nonetheless, there is no systematic review of the relationship between HBV and HCV and CRP levels; thus, in the current meta-analysis, we tried to elucidate this relationship.

Copyright (c) 2020, International Journal of Infection. This is an open-access article distributed under the terms of the Creative Commons Attribution-NonCommercial 4.0 International License (http://creativecommons.org/licenses/by-nc/4.0/) which permits copy and redistribute the material just in noncommercial usages, provided the original work is properly cited. 


\section{Methods}

\subsection{Selection of Test Parameters}

CRP is an acute-phase protein synthesized in the liver in response to inflammation. It is used to determine the progression and development of the disease inflammatory markers. CRP has been shown to be significantly altered in viral hepatitis (1, 2, 7, 9-23). Studies freely accessible in PubMed or ScienceDirect on hepatitis patients between January 1, 2015, and December 31, 2019, were reviewed that are displayed in Figures $1 \mathrm{~A}$ and $\mathrm{B}$ and $2 \mathrm{~A}$ and $\mathrm{B}$ analyzed by the random-effects model.

\subsection{Literature Search}

PubMed database was searched for articles on the association between hepatitis B or C and CRP levels. The keywords used for the search were hepatitis B, hepatitis C, CRP, and inflammation. Full-text articles in English were selected in this study, and their references were also accessed for additional support.

\subsection{Inclusion and Exclusion Criteria}

For this meta-analysis, only studies on hepatitis B or C and estimated plasma CRP levels were included. Inclusion criteria were: (1) reporting the mean level and the corresponding 95\% confidence intervals (CIs) of plasma CRP levels; (2) case series or cross-sectional studies. The flowchart of the study selection process, along with the number of selected and excluded studies at different levels, is indicated in Figure 3.

\subsection{Data Extraction}

The epidemiological guidelines were followed for meta-analysis of observational studies (24). The following data were extracted from each study: the first author's last name, year of publication, the number of patients, the mean, and corresponding 95\% CIs for CRP.

\subsection{Statistical Analysis}

Separate tables were created for hepatitis B and hepatitis C. The pooled means and the corresponding 95\% CIs of CRP was estimated by the random-effects model because data were hypothetically a random selection of all possible studies in the meta-analysis. STATA-16 statistical software was used to prepare the forest plot and funnel plot. to indicate the heterogeneity among studies, $\mathrm{I}^{2}$ value was used; $\mathrm{I}^{2}$ of less than $50 \%$ indicated a higher degree of relationship among studies. Statistical significance was fixed at a $\mathrm{P}$ value of less than $5 \%$. The bias of the study was calculated using the funnel graph, as shown in Figures $1 \mathrm{~B}$ and $2 \mathrm{~B}$.

\section{Results}

Eighteen articles that met the inclusion criteria of our study conducted on the relationship between hepatitis $B$ and hepatitis $C$ and CRP were included in the study. Eleven studies were associated with hepatitis $\mathrm{B}(2,7,15-23)$ and seven were associated with hepatitis $C(1,9-14)$. Table 1 and summarize the pooled mean level, lower limit, upper limit, $\mathrm{I}^{2}$, and $\mathrm{P}$ value of CRP associated with hepatitis $\mathrm{B}$ and hepatitis $C$, respectively. The pooled mean for CRP in hepatitis B was $6.93 \mathrm{mg} / \mathrm{L}$ (95\% CI: 3.04 - 10.81) and for hepatitis C was $2.31 \mathrm{mg} / \mathrm{L}$ (95\% CI: 1.06 - 3.55). Inconsistency was high among the studies, with the $\mathrm{I}^{2}$ of more than $90 \%$ as presented in Tables 1 and 2.

\begin{tabular}{|c|c|c|c|}
\hline \multirow{2}{*}{ Author } & \multirow{2}{*}{ Mean } & \multicolumn{2}{|c|}{ 95\% Confidence Interval } \\
\hline & & LL & UL \\
\hline Shin et al. (22) & 1.35 & 0.292 & 2.408 \\
\hline Hao et al. (7) & 7.63 & 7.042 & 8.218 \\
\hline Metanat et al. (2) & 2.3 & 1.418 & 3.182 \\
\hline MA et al.(23) & 1.53 & 1.079 & 1.981 \\
\hline She et al. (20) & 1.81 & 1.751 & 1.869 \\
\hline Zhu et al.(19) & 9.4 & 3.795 & 15.005 \\
\hline Chen et al. (16) & 12.1 & 3.809 & 20.391 \\
\hline Huanga et al. (18) & 19.9 & 17.881 & 21.919 \\
\hline $\begin{array}{l}\text { Dapaah-Siakwan et } \\
\text { al. (17) }\end{array}$ & 0.27 & 0.192 & 0.348 \\
\hline Chen et al. (15) & 7.31 & 7.075 & 7.545 \\
\hline Zhao et al. (21) & 15 & 13.079 & 16.921 \\
\hline Total & 6.925 & 3.038 & 10.813 \\
\hline
\end{tabular}

Table 2. The Summary of Studies on Patients with Hepatitis C and the Pooled Mean Levels of CRP and the 95\% Confidence Interval (CI)

\begin{tabular}{lccc}
\hline & Mean & \multicolumn{2}{c}{ 95\% Confidence Interval } \\
\cline { 3 - 4 } Author & & LL & UL \\
\hline Bhuiyan et al. (1) & 1.2 & 1.043 & 1.357 \\
Tatar et al. (14) & 3.2 & 2.298 & 4.102 \\
\hline Swanson et al. (13) & 0.7 & 0.19 & 1.21 \\
\hline Faillaci et al. (12) & 2.2 & 1.769 & 2.631 \\
\hline $\begin{array}{l}\text { Goncalvesa et al. } \\
\text { (10) }\end{array}$ & 2.59 & 1.924 & 3.256 \\
\hline Barakat et al. (11) & 5.6 & 4.757 & 6.443 \\
\hline Omran et al. (9) & 0.9 & 0.822 & 0.978 \\
\hline Total & 2.307 & 1.06 & 3.554 \\
\hline
\end{tabular}


A

\begin{tabular}{|c|c|c|}
\hline Study & $\begin{array}{l}\text { Effect Size } \\
\text { with 95\% CI }\end{array}$ & $\begin{array}{c}\text { Weight } \\
(\%)\end{array}$ \\
\hline Shin JH et al & $1.35[0.29, \quad 2.41]$ & 9.49 \\
\hline Hao S et al & $7.63[7.04,8.22]$ & 9.53 \\
\hline Metanat M et al & $2.30 \quad[1.42, \quad 3.18]$ & 9.51 \\
\hline MA L et al & $1.53[1.08,1.98]$ & 9.54 \\
\hline She $S$ et al & $1.81 \quad\left[\begin{array}{ll}1.75, & 1.87]\end{array}\right.$ & 9.55 \\
\hline Zhu SM et al & $9.40[3.79,15.01]$ & 7.97 \\
\hline Chen YL et al & $12.10[3.81,20.39]$ & 6.66 \\
\hline Huanga SS et al & $19.90[17.88,21.92]$ & 9.31 \\
\hline Siakwan FD et al & $0.27[0.19,0.35]$ & 9.55 \\
\hline CHEN X.-L et al & $7.31 \quad[7.07, \quad 7.55]$ & 9.55 \\
\hline Zhao X et al & $15.00[13.08,16.92]$ & 9.34 \\
\hline Overall & $6.93[3.04,10.81]$ & \\
\hline
\end{tabular}

Heterogeneity: $\mathrm{T}^{2}=41.18, \mathrm{I}^{2}=99.97 \% \mathrm{H}^{2}=3966.6$

Test of $\theta_{\mathrm{i}}=\theta_{\mathrm{j}}: \mathrm{Q}(10)=4336.25, \mathrm{p}=0.00$

Test of $\theta=0: z=3.49, p=0.00$

Random-effects REML Model
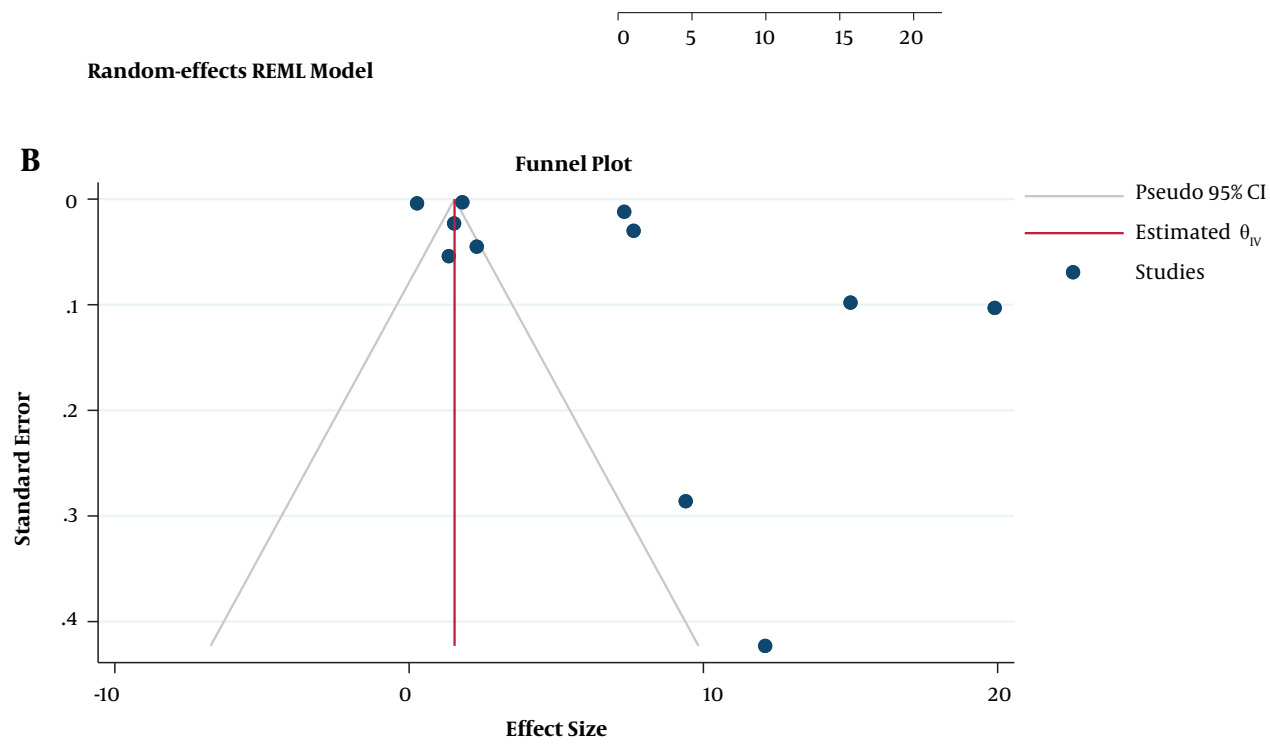

Figure 1. A, Forest plot of random-effects meta-analysis for C-reactive protein (CRP) in hepatitis B; B, Funnel plot with pseudo 95\% confidence interval for C-reactive protein (CRP) in hepatitis B.

\subsection{Hepatitis $B$}

Eleven studies showed a statistically significant association between CRP levels and hepatitis B. The overall CRP mean level in all studies was $6.93 \mathrm{mg} / \mathrm{L}$ (95\% CI: 3.04 -10.81), with $\mathrm{I}^{2}$ of $99.97 \%$, as shown in Figure 1A. The publication bias was high because most of the studies were located outside of the funnel figure, as shown in Figure 1B.

\subsection{Hepatitis $C$}

CRP reported in all seven studies on its relationship with hepatitis C, had disclosed a statistically significant association. The overall CRP mean level in all studies was 2.31 $\mathrm{mg} / \mathrm{L}$ (95\% CI: 1.06 - 3.55), with $\mathrm{I}^{2}$ of $99.36 \%$, as shown in Figure $2 \mathrm{~A}$. The publication bias was high because most of the studies were located outside of the funnel figure, as shown in Figure 2B.

\section{Discussion}

The current meta-analysis, to our knowledge, is the first meta-analysis evaluating the prognostic value of CRP in patients with viral hepatitis. The pooled mean level of CRP in 11 studies on hepatitis B and 7 studies on hepatitis C were retrieved in this study. We assumed that the samples were selected randomly; thus, the random-effects model 

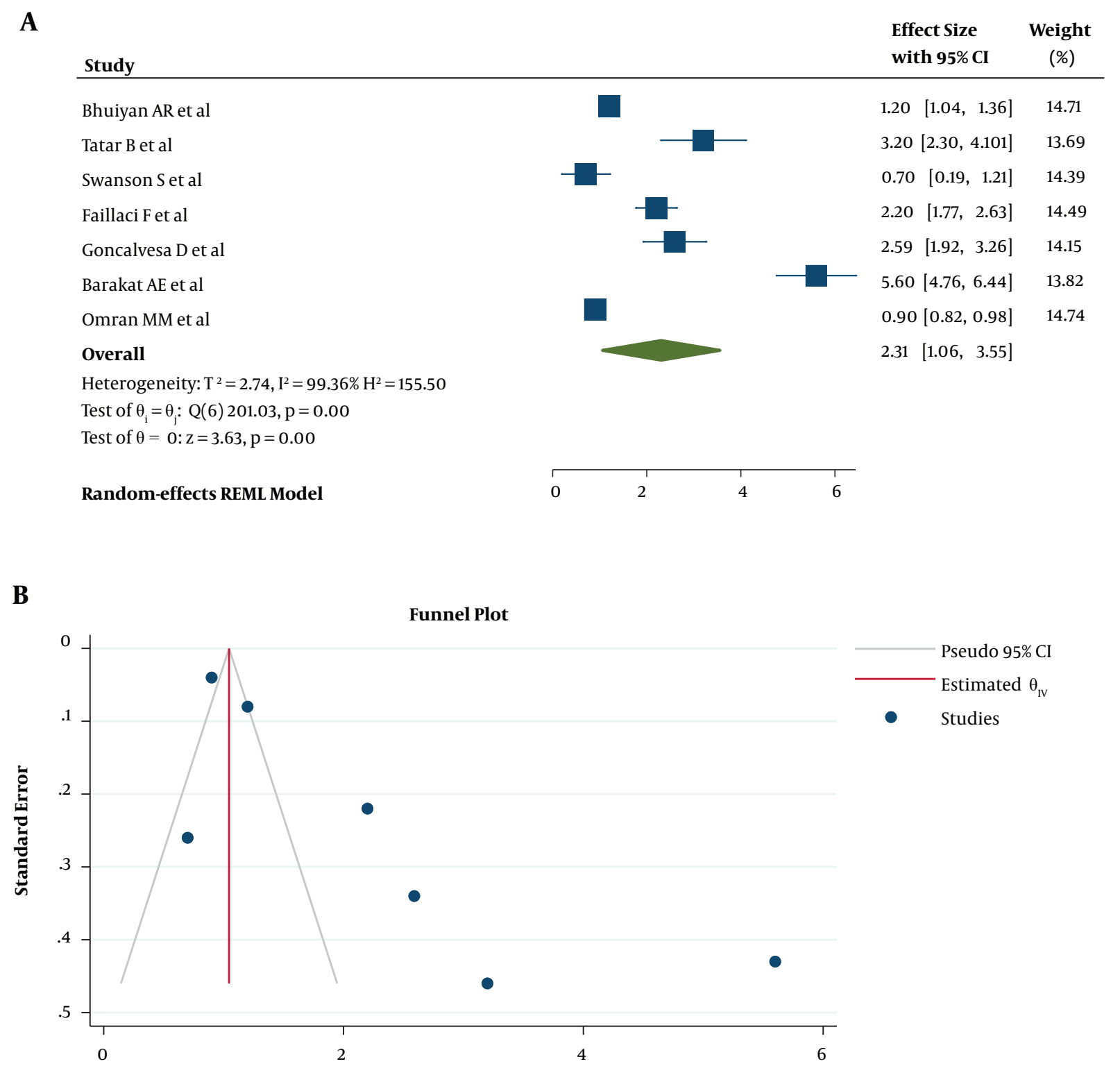

Effect Size

Figure 2. A, Forest plot of random-effects meta-analysis for C-reactive protein (CRP) in hepatitis C; B, funnel plot with pseudo $95 \%$ confidence interval for C-reactive protein (CRP) in hepatitis C.

was used. The high degree of heterogeneity among the studies was due to the diversity of locations, cultures, economic status, and different duration of the studies.

As reported in previous studies, CRP is an acute phase reactant protein synthesized by hepatocytes in response to inflammatory reactions, such as tissue injury, cardiovascular disease, and viral and bacterial infections (5).

Our meta-analysis results indicated that the pooled mean level of CRP in hepatitis B was higher than the normal range, which could be due to poor host immune responses against the hepatitis B virus. This can cause a failure in the reduction of infection by the body and trigger the production of cytokines storms leading to inflammation and CRP. This finding is consistent with those reported by Hao et al. (7), Zhu et al. (19), Chen et al. (16), Huanga et al. (18), Chen et al. (15) who declared an increase in CRP levels 


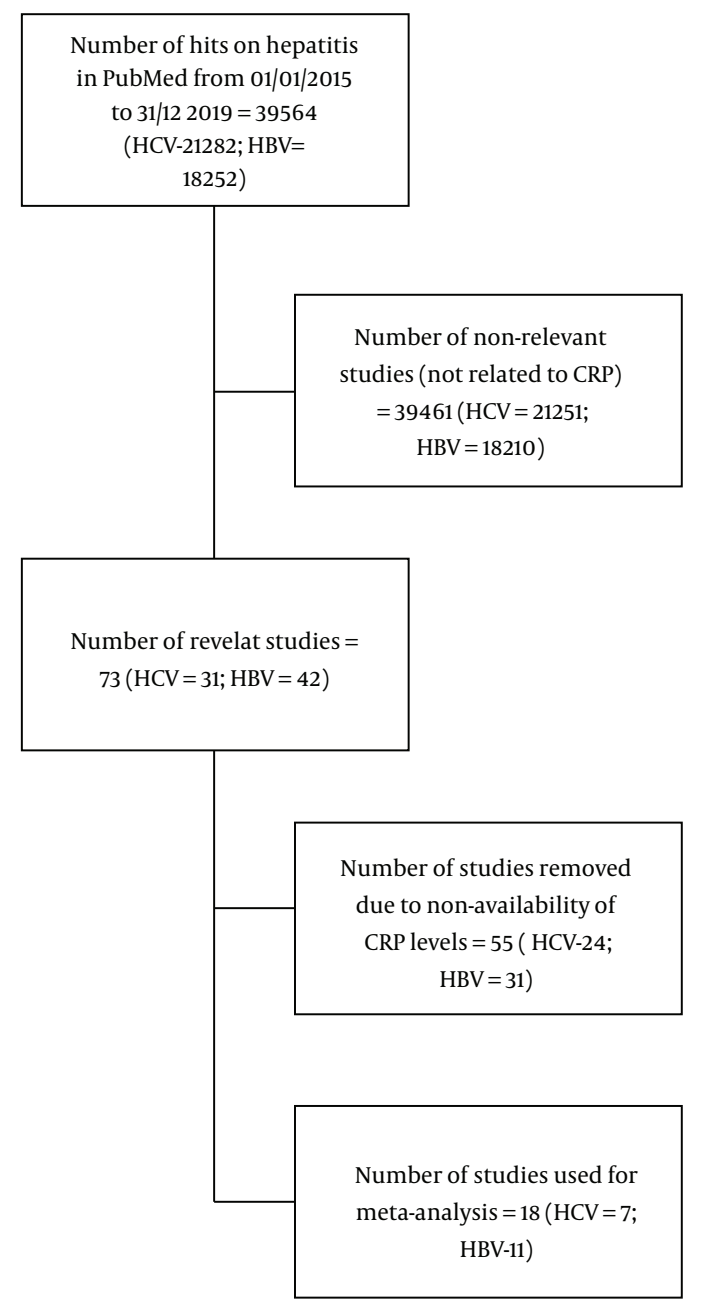

Figure 3. Flowchart of the process of study selection

in hepatitis B patients. However, studies done by Shin et al. (22), Metanat et al. (2), MA et al. (23), She et al. (20), DapaahSiakwan et al. (17), and Zhao et al. (21) showed no increase in CRP levels in hepatitis B patients.

In our study, the pooled mean level of CRP was within the normal range for hepatitis $\mathrm{C}$ patients. The possible mechanism is that in patient chronically infected with HCV alterations in local immune response of the liver and decreased production of CRP resulted in CRP levels within normal range (25). Studies conducted by Bhuiyan et al. (1), Tatar et al. (14), Swanson et al. (13), Faillaci et al. (12), Goncalvesa et al. (10), and Omran et al. (9) showed the CRP levels within normal range; however, Barakat et al. (11) reported an increase in CRP levels in hepatitis $\mathrm{C}$ patients.

\section{Conclusions}

This study reported the pooled mean level of CRP in hepatitis $B$ and hepatitis $C$ as the most common causes of viral hepatitis. The overall mean level reported in this study could be useful in measurement of liver damage and prognosis of viral hepatitis. The pooled CRP mean level for hepatitis $C$ was in the normal range; however, serum level of CRP (pooled mean) was found high in hepatitis B patients. Therefore, we suggest that the pooled mean level of CRP could be useful for the determination of the prognosis of hepatitis B and its related complications.

\section{Footnotes}

Authors' Contribution: Study concept and design: $\mathrm{AB}$ and SS. Analysis and interpretation of data $A B$ and SS. Drafting of the manuscript: PK. Critical revision of the manuscript for important intellectual content: $A B$ and SS. Statistical analysis: AB.

Conflict of Interests: None.

Funding/Support: None.

\section{References}

1. Bhuiyan AR, Mitra AK, Ogungbe O, Kabir N. Association of HCV Infection with C-Reactive Protein: National Health and Nutrition Examination Survey (NHANES), 2009(-)2010. Diseases. 2019;7(1). doi: 10.3390/diseases7010025. [PubMed: 30813467]. [PubMed Central: PMC6473745].

2. Metanat M, Tabatabaei SM, Alenabi A, Amirian Mojarad MH, Sepehri Rad N, Pahlavani E. Diagnostic Value of the Quantitative Titer of High-Sensitivity C-Reactive Protein in the Detection of Clinical Stages of Chronic Hepatitis B Infection. Int J Infect. 2016;4(2). doi: 10.5812/iji.39736.

3. Hyun Kim B, Ray Kim W. Epidemiology of Hepatitis B Virus Infection in the United States. Clin Liver Dis (Hoboken). 2018;12(1):14. doi: 10.1002/cld.732. [PubMed: 30988901]. [PubMed Central: PMC6385902].

4. Yu Y, Gong R, Mu Y, Chen Y, Zhu C, Sun Z, et al. Hepatitis B virus induces a novel inflammation network involving three inflammatory factors, IL-29, IL-8, and cyclooxygenase-2. J Immunol. 2011;187(9):4844-60. doi: 10.4049/jimmunol.1100998. [PubMed: 21957142].

5. Sproston NR, Ashworth IJ. Role of C-Reactive Protein at Sites of Inflammation and Infection. Front Immunol. 2018;9:754. doi: 10.3389/fimmu.2018.00754. [PubMed: 29706967]. [PubMed Central: PMC5908901].

6. Jiang SJ, Tsai PI, Peng SY, Chang CC, Chung Y, Tsao HH, et al. A potential peptide derived from cytokine receptors can bind proinflammatory cytokines as a therapeutic strategy for anti-inflammation. Sci Rep. 2019;9(1):2317. doi: 10.1038/s41598-018-36492-z. [PubMed: 30783144]. [PubMed Central: PMC6381106].

7. Hao S, Wang Y, Gao G, Li Z. Hepatitis B Virus Upregulates the Expression of C-reactive Protein Both in vivo and in vitro. Ann Clin Lab Sci. 2017;47(4):432-5. [PubMed: 28801369]. 
8. de Souza Pires-Neto O, da Silva Graca Amoras E, Queiroz MAF, Demachki S, da Silva Conde SR, Ishak R, et al. Hepatic TLR4, MBL and CRP gene expression levels are associated with chronic hepatitis C. Infect Genet Evol. 2020;80:104200. doi: 10.1016/j.meegid.2020.104200. [PubMed: 31962161].

9. Omran MM, Emran TM, Farid K, Eltaweel FM, Omar MA, Bazeed FB. An Easy and Useful Noninvasive Score Based on alpha-1-acid Glycoprotein and C-Reactive Protein for Diagnosis of Patients with Hepatocellular Carcinoma Associated with Hepatitis C Virus Infection. J Immunoassay Immunochem. 2016;37(3):273-88. doi:10.1080/15321819.2015.1132229. [PubMed: 26685049].

10. Goncalves D, Lima C, Ferreira P, Costa P, Costa A, Figueiredo W, et al. Orange juice as dietary source of antioxidants for patients with hepatitis C under antiviral therapy. Food Nutr Res. 2017;61(1):1296675. doi: 10.1080/16546628.2017.1296675. [PubMed: 28469541]. [PubMed Central: PMC5404424].

11. Barakat AAE, Nasr FM, Metwaly AA, Morsy S, Eldamarawy M. Atherosclerosis in chronic hepatitis $C$ virus patients with and without liver cirrhosis. Egypt Heart J. 2017;69(2):139-47. doi: 10.1016/j.ehj.2016.10.004. [PubMed: 29622968]. [PubMed Central: PMC5839344].

12. Faillaci F, Marzi L, Critelli R, Milosa F, Schepis F, Turola E, et al. Liver Angiopoietin-2 Is a Key Predictor of De Novo or Recurrent Hepatocellular Cancer After Hepatitis C Virus Direct-Acting Antivirals. Hepatology. 2018;68(3):1010-24. doi: 10.1002/hep.29911. [PubMed: 29604220]. [PubMed Central: PMC6175123].

13. Swanson S, Ma Y, Scherzer R, Huhn G, French AL, Plankey MW, et al. Association of HIV, Hepatitis C Virus, and Liver Fibrosis Severity With the Enhanced Liver Fibrosis Score. J Infect Dis. 2016;213(7):107986. doi: 10.1093/infdis/jiv567. [PubMed: 26621911]. [PubMed Central: PMC4779303].

14. Tatar B, Kose S, Pala E, Tatar E. Inflammatory Biomarkers and Liver Histopathology in Non-Uremic and Uremic Chronic Hepatitis C Patients. Acta Medica (Hradec Kralove). 2017;60(2):71-5. doi: 10.14712/18059694.2017.96. [PubMed: 28976873].

15. Chen XL, Han YD, Wang H. Relations of hepatic steatosis with liver functions, inflammations, glucolipid metabolism in chronic hepatitis B patients. Eur Rev Med Pharmacol Sci. 2018;22(17):5640-6. doi: 10.26355/eurrev_201809_15830.[PubMed:30229840].

16. Chen YL, Lin JZ, Mo YQ, Ma JD, Li QH, Wang XY, et al. Deleterious role of hepatitis $\mathrm{B}$ virus infection in therapeutic response among patients with rheumatoid arthritis in a clinical practice setting: a casecontrol study. Arthritis Res Ther. 2018;20(1):81. doi: 10.1186/s13075-018-
1548-5. [PubMed: 29720221]. [PubMed Central: PMC5932798].

17. Dapaah-Siakwan F, Gunasekaran A, Schutzman DL. C-reactive protein levels following hepatitis B vaccine in healthy newborns. J Perinatol. 2016;36(3):231-4. doi: 10.1038/jp.2015.160. [PubMed: 26562368].

18. Huang SS, Xie DM, Cai YJ, Wu JM, Chen RC, Wang XD, et al. C-reactive protein-to-albumin ratio is a predictor of hepatitis $\mathrm{B}$ virus related decompensated cirrhosis: time-dependent receiver operating characteristics and decision curve analysis. Eur J Gastroenterol Hepatol. 2017;29(4):472-80. doi: 10.1097/MEG.0000000000000807. [PubMed: 27984322].

19. Zhu S, Waili Y, Qi X, Chen Y, Lou Y, Chen B. Serum C-reactive protein predicts early mortality in hospitalized patients with HBV-related decompensated cirrhosis. Medicine (Baltimore). 2017;96(4). e5988. doi: 10.1097/MD.0000000000005988. [PubMed: 28121954]. [PubMed Central: PMC5287978].

20. She S, Xiang Y, Yang M, Ding X, Liu X, Ma L, et al. C-reactive protein is a biomarker of AFP-negative HBV-related hepatocellular carcinoma. Int J Oncol. 2015;47(2):543-54. doi: 10.3892/ijo.2015.3042. [PubMed: 26058824].

21. Zhao X, Luo J, Li B, Liu S, Li D. The association between preoperative serum C-reactive protein and hepatocellular carcinoma recurrence in patients with chronic hepatitis B virus (HBV) infection-a retrospective study. PLoS One. 2015;10(1). e0116909. doi: 10.1371/journal.pone.0116909. [PubMed: 25602444]. [PubMed Central: PMC4300186].

22. Shin JH, Yu E, Kim EN, Kim CJ. C-reactive Protein Overexpression in the Background Liver of Hepatitis B Virus-Associated Hepatocellular Carcinoma Is a Prognostic Biomarker. J Pathol Transl Med. 2018;52(5):26774. doi: 10.4132/jptm.2018.07.14. [PubMed: 30056637]. [PubMed Central: PMC6166009].

23. Ma LN, Liu XY, Lu ZH, Wu LG, Tang YY, Luo X, et al. Assessment of highsensitivity C-reactive protein tests for the diagnosis of hepatocellular carcinoma in patients with hepatitis B-associated liver cirrhosis. Oncol Lett. 2017;13(5):3457-64. doi: 10.3892/ol.2017.5890. [PubMed: 28521452]. [PubMed Central: PMC5431324].

24. Jussawalla DJ, Deshpande VA. Evaluation of cancer risk in tobacco chewers and smokers: An epidemiologic assessment. Cancer. 1971;28(1):244-52.

25. Shah S, Ma Y, Scherzer R, Huhn G, French AL, Plankey M, et al. Association of HIV, hepatitis $C$ virus and liver fibrosis severity with interleukin-6 and C-reactive protein levels. AIDS. 2015;29(11):132533. doi: 10.1097/QAD.0000000000000654. [PubMed: 25870985] [PubMed Central: PMC4478137]. 